\title{
Hybrid Wind-Battery System for a Stand-Alone Wind Energy Conversion System
}

\author{
Nethravathi S Gaddi ${ }^{1}$, A V Malini ${ }^{2}$ \\ PG Student, Dept of Electrical Engineering, University BDT College of Engg, Davangere, India ${ }^{1}$ \\ Associate Professor, Dept of Electrical Engineering, University BDT College of Engg, Davangere, India ${ }^{2}$
}

\begin{abstract}
This paper proposes a hybrid wind-battery system for stand-alone wind energy conversion system. Present energy demand heavily depends on the conventional sources. But the frequent increase in the price and limited availability of conventional sources has shifted the focus toward non-conventional energy sources. Among the available alternative energy sources, wind energy is considered to be one of the efficient and proven technologies. With a competitive cost for electricity generation, wind energy conversion system (WECS) is used in present scenario meet both grid-connected and stand-alone load demands. However, wind flow by nature is intermittent. In order to ensure continuous supply of power suitable storage technology is used as backup. In laboratory rigorous test need to be carried out to develop efficient control strategy for wind energy conversion system (WECS). In this paper to meet the dc load the hybrid wind battery system is investigated. State of charge is developed to confirm controlled charging and discharging of battery which acts as a charge controller for battery bank. Pitch management technique is used for the mechanical safety of the WECS. The control schemes are integrated effectively and tested for dc load and wind profiles in MATLAB/SIMULINK.
\end{abstract}

Keywords: Maximum power point tracking (MPPT), pitch control, wind energy conversion system (WECS).

\section{INTRODUCTION}

Energy is the essential key element for the development. At present scenario depletion of available conventional energy sources and concern towards environmental degradation, has shifted the focus on renewable sources to meet ever increasing energy demand. Due to a low production cost of electricity wind energy is considered to be one of the potential sources of fresh energy for the longer term. However the nature of wind flow is intermittent. So continuous testing need to be carried out in laboratory to develop efficient control strategy for WECS. The study of WECS and the associated controllers are becoming more and more significant with each passing.

Nowadays, many stand-alone loads are powered by renewable source of energy. With this revived interest in wind technology for stand-alone applications, a great deal of research is being carried out to choose a suitable generator for stand-alone WECS. The major advantage of asynchronous machine is that, with variable speed operation allows extracting maximum power from WECS and reducing the torque fluctuations. Induction generator with a lower unit cost, inherent robustness, and operational simplicity is considered as the most viable option as wind turbine generator (WTG) for off grid applications. However, the initiation generator need electrical device bank for excitation at isolated locations. The excitation development of self-excited induction generator (SEIG) is explained. The power output of the induction generator depends on the wind flow which by nature is intermittent. Both amplitude and frequency of the induction generator voltage vary with wind speed. Such indiscriminately varying voltage when comes in touch with the load directly can give rise to flicker and instability at the load end. So, the wind energy conversion system is integrated with the load by power electronic converters in order to ensure a regulated load voltage. Due to the stochastic characteristics of the wind power, a wind energy conversion system needs to have energy storage system.

\section{CONTROL SCHEMES}

We know that the wind flow is stochastic in nature. To avoid the voltage flicker and instability in WECS load, it is integrated with ac-dc-dc device. The control scheme for a complete hybrid wind- battery system includes the charge Controller circuit for series banks and pitch control scheme to confirm WT optimal operations inside the rated price. The control schemes ensure effective control of the WECS against all potential disturbances.

The following 2 types of control strategies which are used in hybrid wind-battery system in stand-alone wind energy conversion.

a. Pitch control Scheme.

b. MPPT technique 


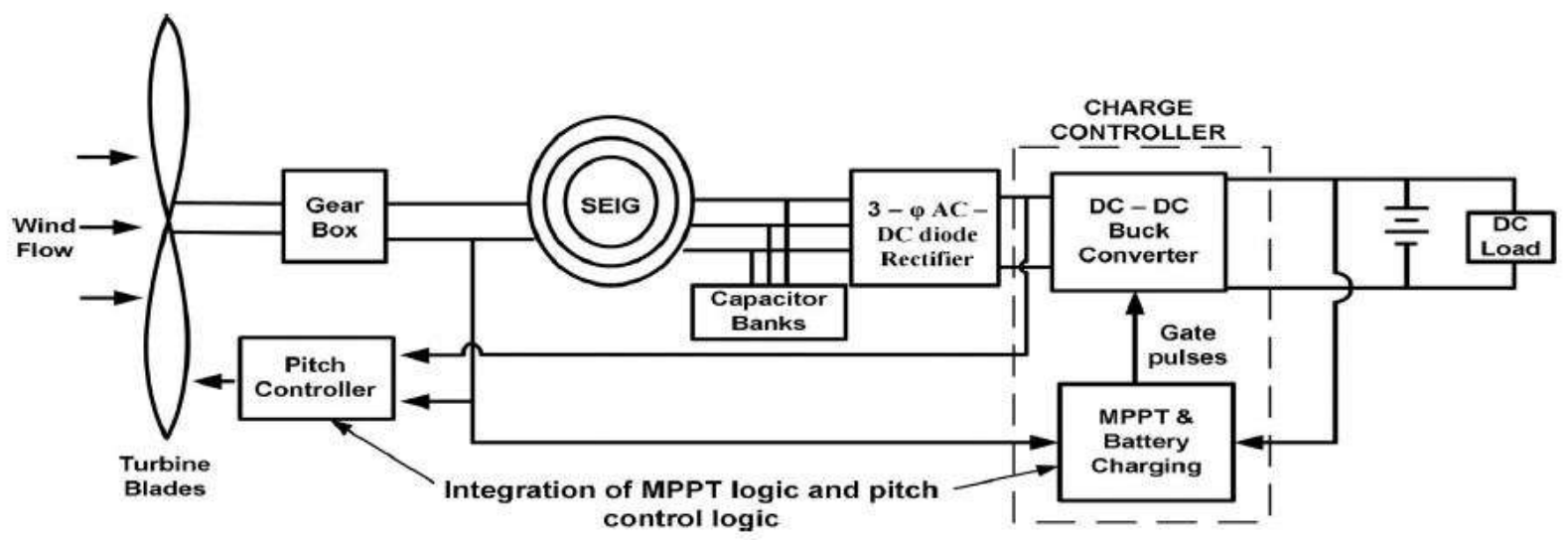

Figure 1: Layout of hybrid wind-battery system for a stand-alone dc load.

\section{A. Pitch Control}

In general the cut-off wind speed of a WT is higher compared to the rated wind speed. If the WT is allowed to complete variable wind speed during absence of control scheme, the rated speed of the shaft will be exceeded to its rated value, which causes break in the blades. So, it's very much essential to keep a check on and to control speed and power at wind speed, which is higher than the rated wind speed. This can be achieved by using pitch angle control scheme to adjust the blades of WT. so, pitch control technique can gain control over the power output by dropping the coefficient of power at high wind speeds. The pitch controller ensures the safe operation of WECS by the help of pitch command/signal due to variation in the engine rotation speed, power and output voltage of the rectifier. To calculate the error, the p.u value of each input is compared with 1 and using PI controller the errors are tuned. From each PI controller the MAX block chooses the maximum output which is then passed on to a limiter to generate the pitch command for the WT. The limited value is used for the comparison of actual pitch command. The pitch command is set to zero if the limit is lower. The error is generated if the actual pitch command is above/greater than or below/less than the actual specified limit. This is multiplied with the error obtained from each of the comparator. To determine the switching logic for integrator the product is compared with zero. To avoid integrator saturation this technique is carried out.

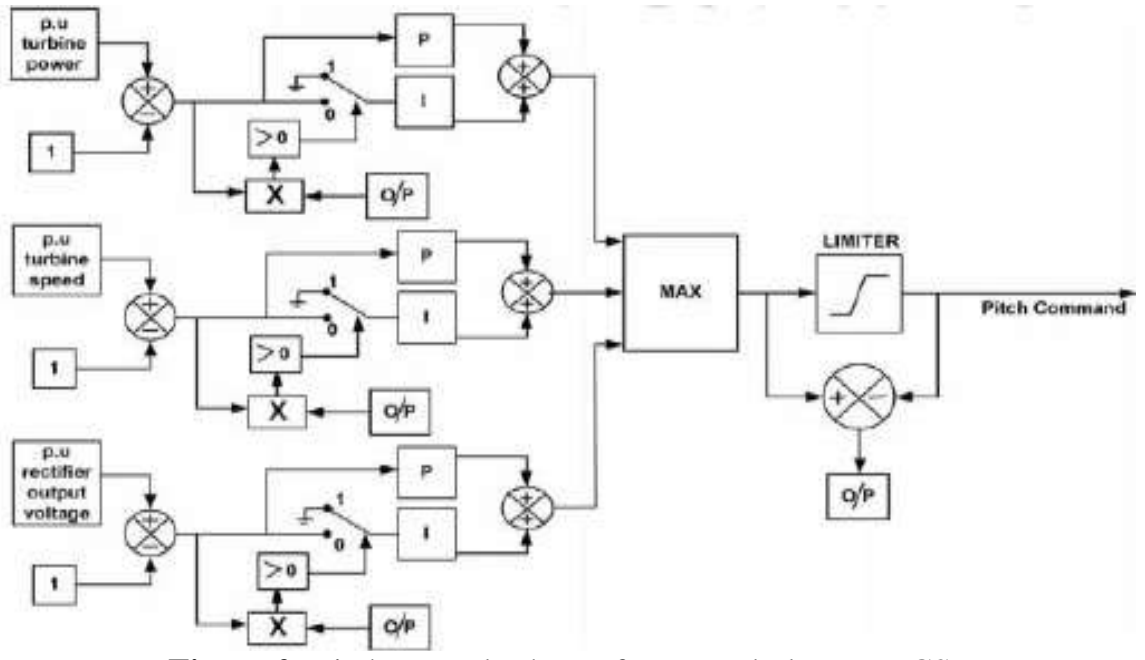

Figure 2: Pitch control scheme for a stand-alone WECS

B. MPPT Technique

MPPT is referred as Maximum Power Point Track, it is associated with electronic system that operates the electrical phenomenon (PV) module in an effective manner which permits the modules to get all the ability they're capable of. MPPT isn't a mechanical system; it is an electronic system which can change the electrical operating purpose of the modules through which the power is made much easily accessible. The power harvested from the technique is offered to battery to increase the battery charge current. MPPT can be used with the following system at same time automatically; however the two techniques are totally different. To acknowledge the work of MPPT let's assume initial operation of the-nonMPPT-charge controller. Once a standard controller charges a discharged battery, it automatically 
Vol. 5, Issue 5, May 2017

connects the modules to the battery. This modules/system gains control over the battery voltage, sometimes the operating voltage at the modules are not cable of producing efficient power output. The most efficient power within the bounded conditions can be extracted using MPPT or by following algorithmic rule which is encloses the responsible controllers. The power generated by the voltage at the wind module which is termed as maximum power point/ peak power voltage. The power varies with the wind system voltage. MPPT is associated with electronic DC to DC device that optimizes the operation of the battery bank or utility grid. DC output in the beginning modified and brought down to the lower voltage required to charge batteries.

\section{SIMULATION MODEL}

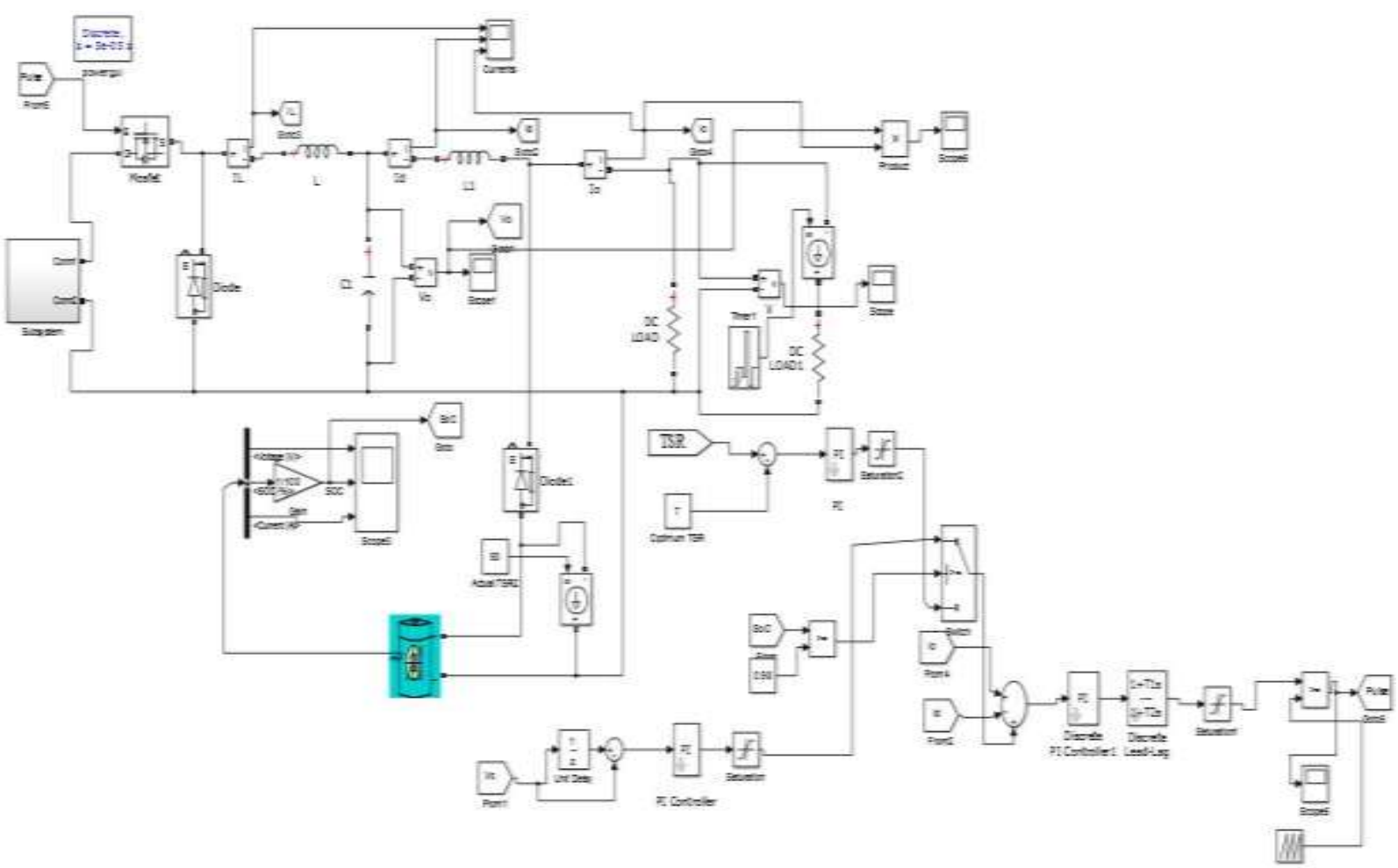

Figure 3: Final MPPT Model

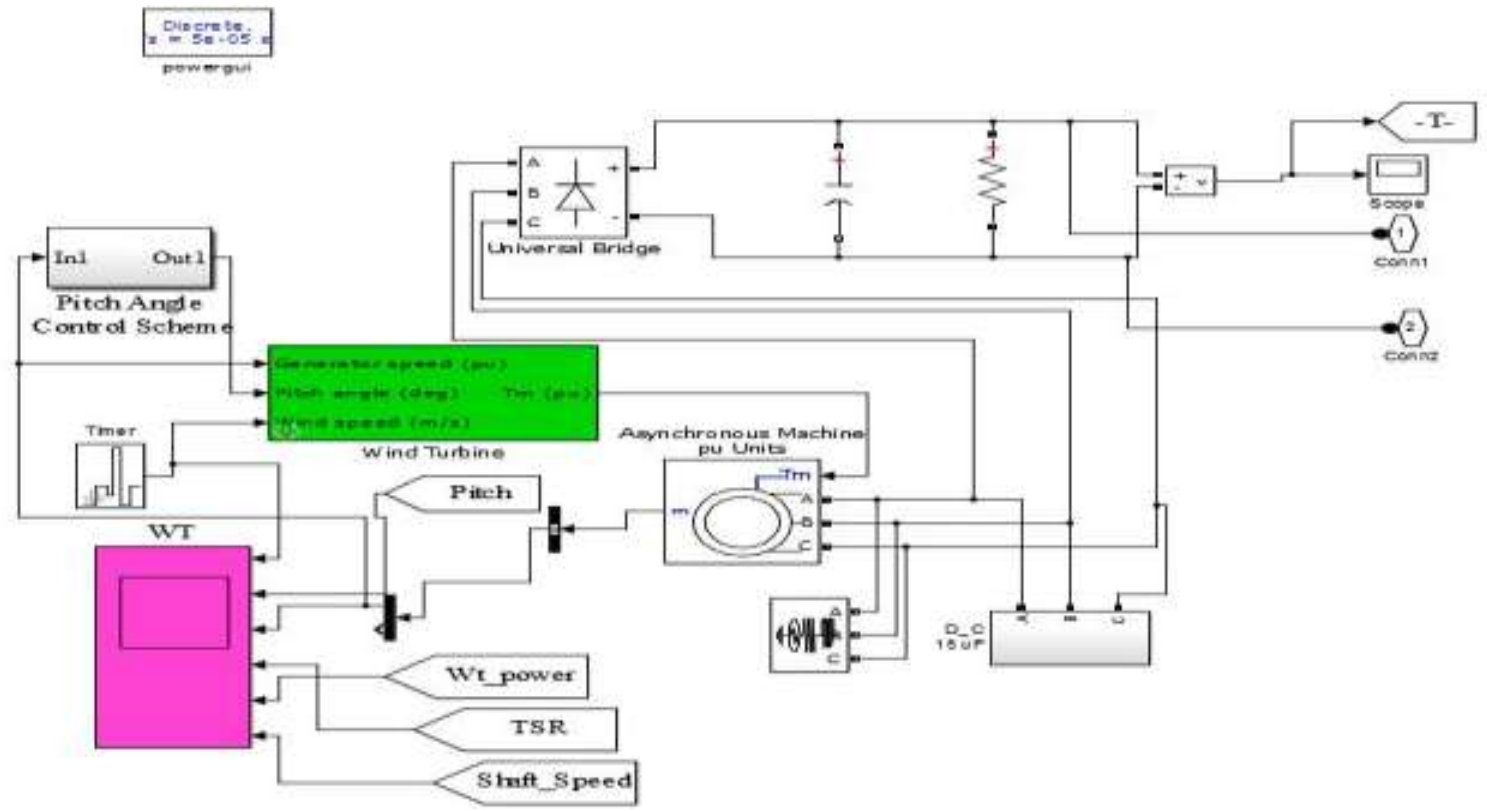

Figure 4: Wind model. 
International Journal of Innovative Research in Electrical, Electronics, Instrumentation and Control Engineering

ISO 3297:2007 Certified

Vol. 5, Issue 5, May 2017

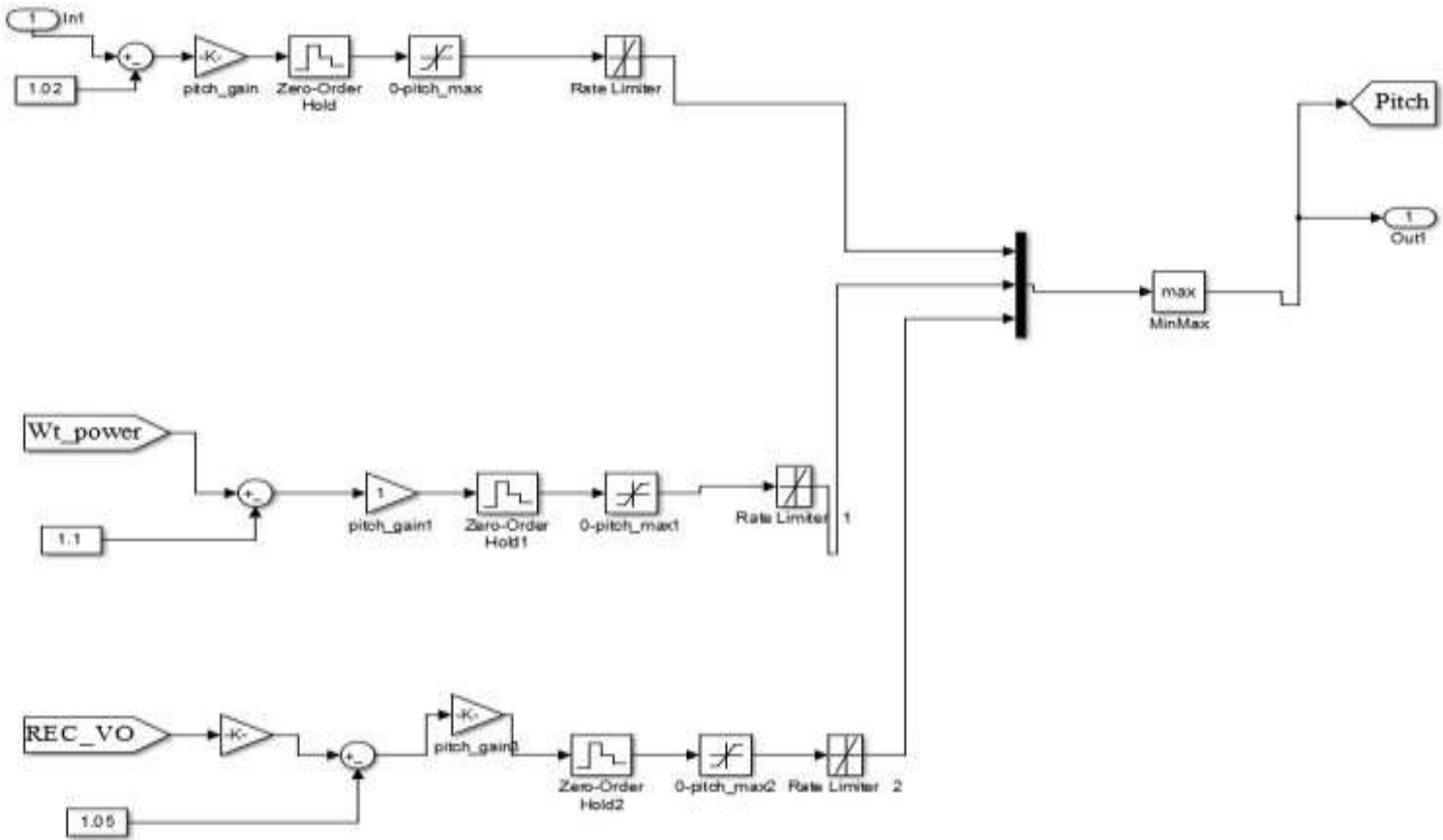

Figure 5: Pitch control scheme.

IV. SIMULATION RESULTS

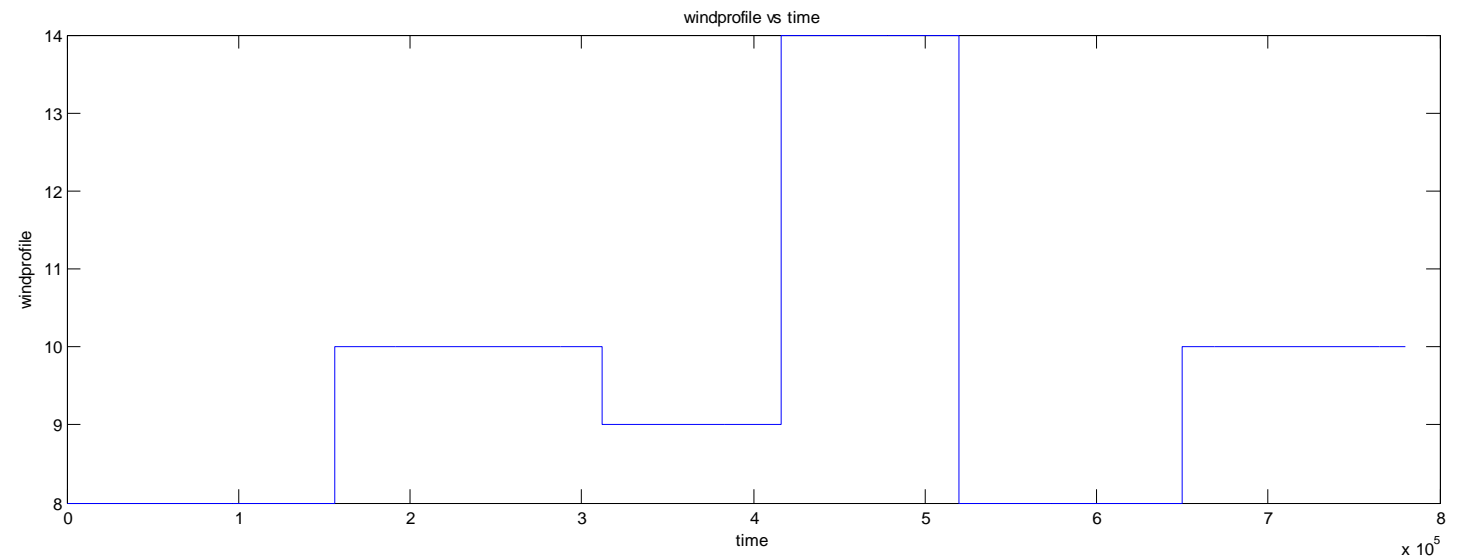

Figure 6 (a): wind profile.

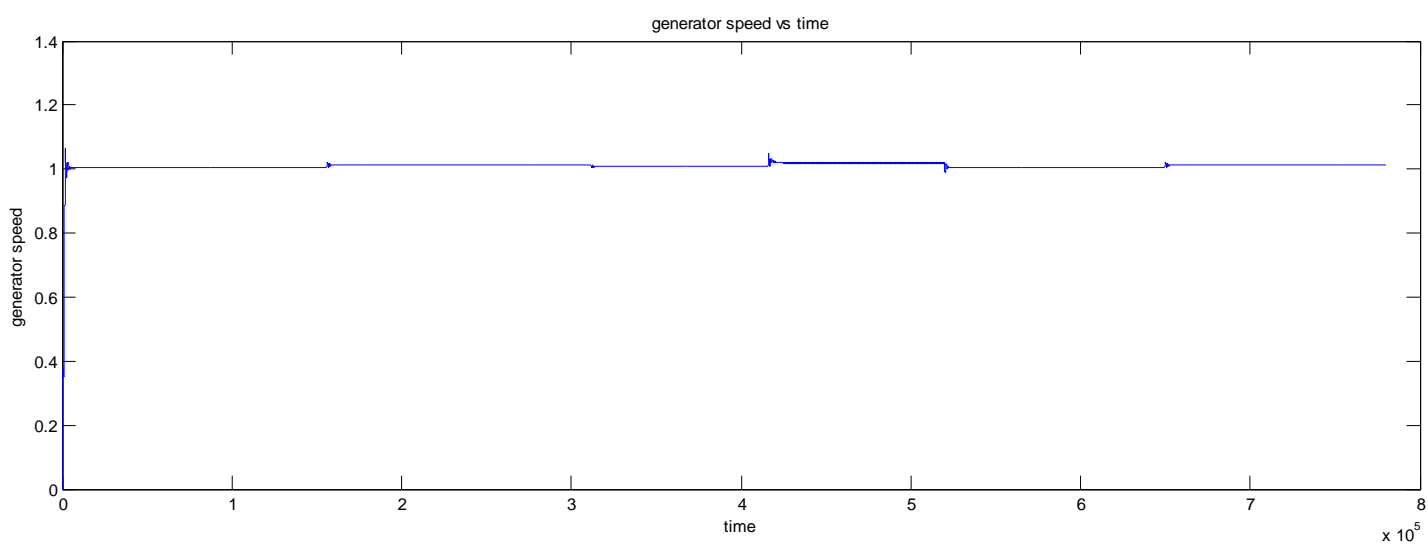

Figure 6 (b): Generator speed. 


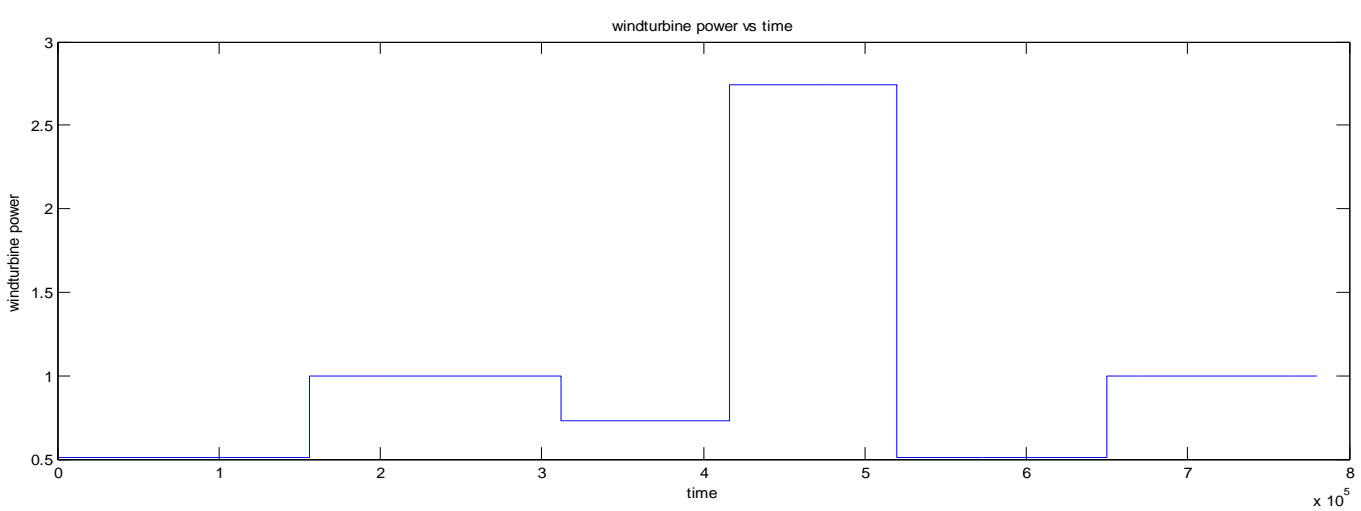

Figure 6 (c): turbine power.

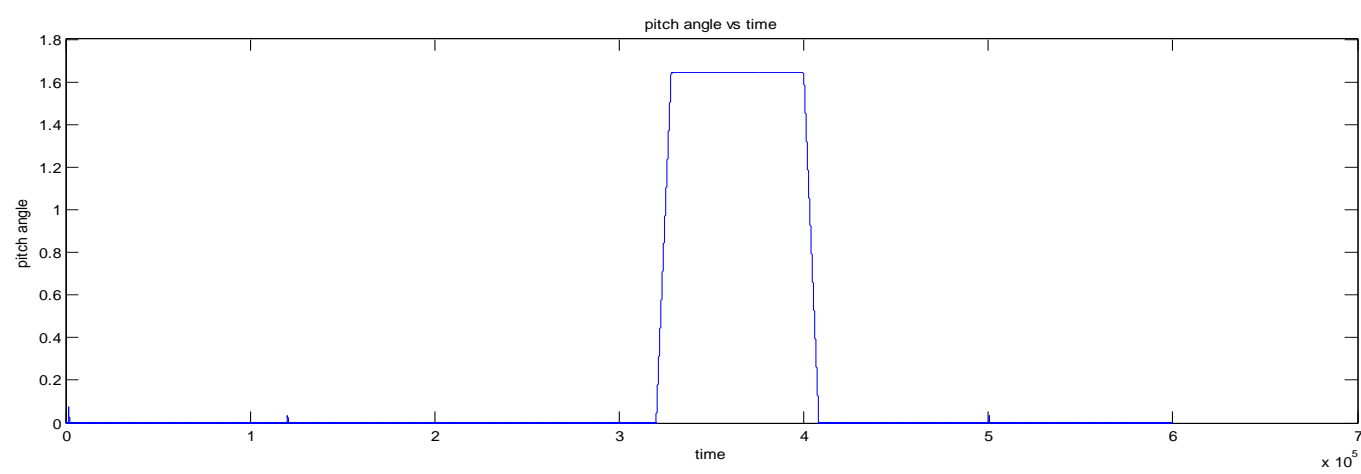

Figure 6 (d): pitch angle

Figure 6 (a) is wind profile with different amplitude wrt to time, whereas 6 (b) (c) shows the simulation results for the respective wind profile and Figure 6 (d) shows the pitch angle variation for the higher speed or for the high amplitude of wind profile for the safety purpose and for maximum power extract

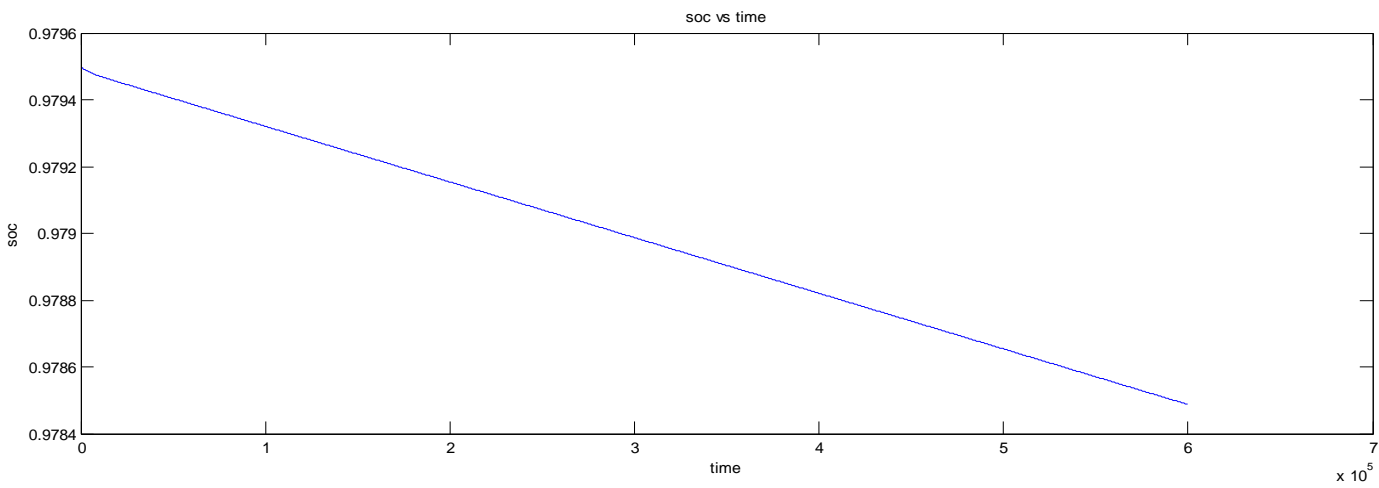

Figure 6 (e): soc of battery.

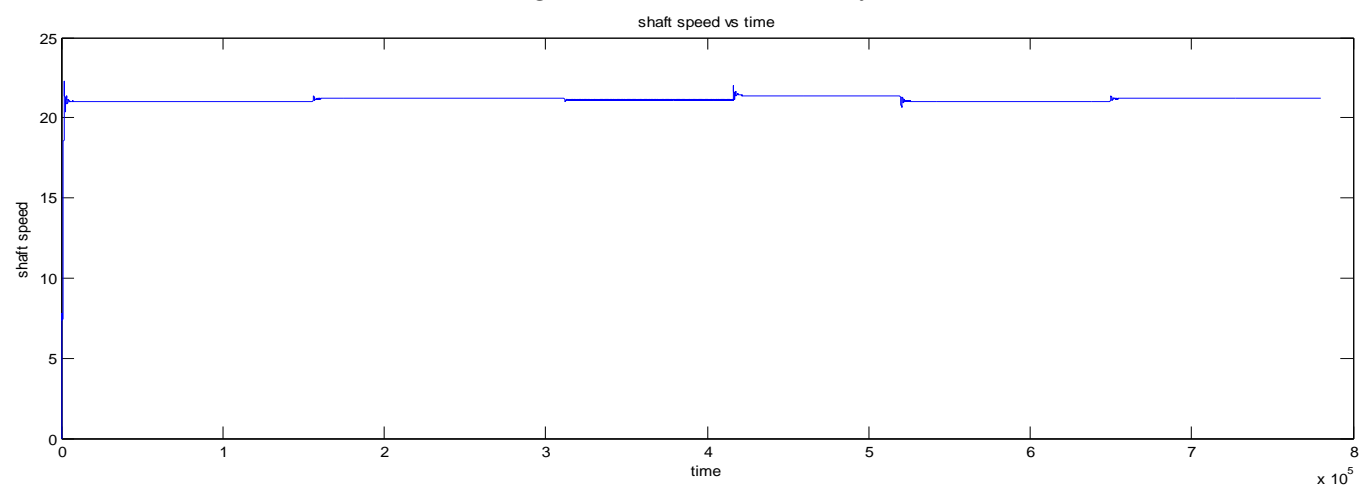

Figure 6 (f): shaft speed. 


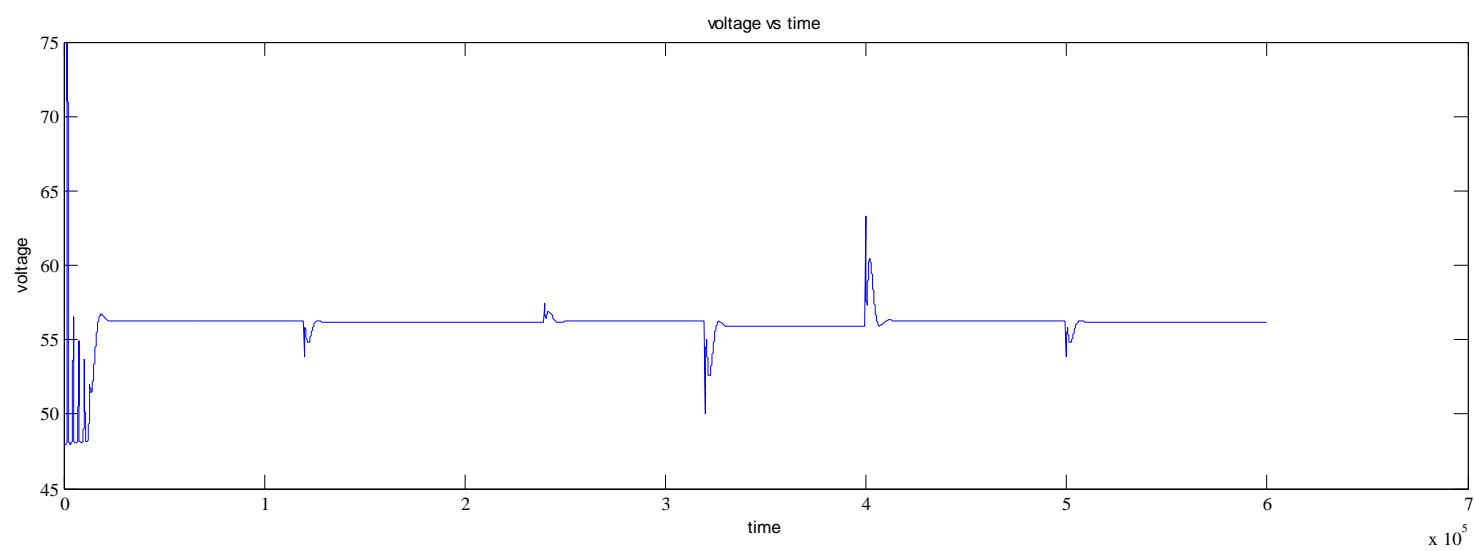

Figure $6(\mathrm{~g})$ : voltage.

Figure 6 (e) (f) (g) shows the simulation results for the respective different amplitude wind profile which is shown in 6(a). In 6 (e) the charge tried to maintain around $97-98 \%$ where as the shaft speed is about 20rps wrt to time 6(f) shows the voltage across the load.

\section{RESULT AND DISCUSSION}

A wind energy conversion system needs to be efficient to ensure continuous power Flow to the load. The effectiveness can be achieved by integrating the hybrid wind-battery system with suitable control logic. This includes the charge control logic and the pitch control logic. The charge controller regulates the charging and discharging rate of the battery bank while the pitch controller controls the wind turbine action during high wind speed conditions or in case of a power mismatch. Both the control strategy are integrated with the hybrid system and simulated with various wind profiles to validate the efficacy of the system.

\section{CONCLUSION AND FUTURE SCOPE}

Wind energy conversion system (WECS) is currently not able to meet the demand of grid-connected and stand-alone loads. So, continuous power flow to the load cannot make sure by using WECS. So to meet the demand at any instances proper devices or system is needed. Therefore, a hybrid wind-battery system is chosen to provide the required load power. The control scheme established includes charge management of battery using MPPT and pitch angle management. To charge the battery bank during a controlled manner, the charge controller tracks the most power and offered to charge to battery. The pitch angle scheme regulates the pitch angle to reduce the output power of WT during the power mismatch conditions. The Electrical and mechanical safety of WT is assured by MPPT and pitch control management. The bcuk converter during over current situation can be protected using programmed control technique. Using MATLAB/SIMULINK Hybrid wind-battery system with control logic is developed and tested for various wind profiles. The developed model reduces the cost and maximum efficiency can be attained. Wind power is greater source of distributed energy production. This model with use of minimum source of utilization is able to will give maximum output.

\section{REFERENCES}

[1] A. D. Sahin, "Progress and recent trends in wind energy," Progress in Energy Combustion Sci., vol. 30, no. 5, pp. 501-543, 2004.

[2] R. Saidur, M. R. Islam, N. A. Rahim, and K. H. Solangi, “A review on global wind energy policy,” Renewable Sustainable Energy Rev., vol. 14, no. 7, pp. 1744-1762, Sep. 2010.

[3] M. T. Ameli, S. Moslehpur, and A. Mirzale, "Feasibility study for replacing asynchronous genrators with synchronous generators in wind farm power stations," in Proc. IAJC - IJME, Int. Conf. Eng. Technol., Music City Sheraton, Nashville, TN, US, ENT paper 129Nov. 17-19, 2008.

[4] R. C. Bansal, "Three-phase self-excited induction generators: Anoverview," IEEE Trans. Energy Convers., vol. 20, no. 2, pp. 292-299, Jun. 2005 .

[5] A. M. D. Broe, S. Drouilhet, and V. Gevorgian, "A peak power tracker for small wind turbines in battery charging applications," IEEE Trans. EnergyConvers., vol. 14, no. 4, pp. 1630-1635, Dec. 1999.

[6] K. Y. Lo, Y. M. Chen, and Y. R. Chang, "MPPT battery charger for standalone wind power system," IEEE Trans. Power Electron., vol. 26, no. 6, pp. 1631-1638, Jun. 2011.

[7] E. Muljadi and C. P. Butterfield, "Pitch-controlled variable-speed wind turbine generation," IEEE Trans. Ind. Appl., vol. 37, no. 1, pp. 240246 ,

[8] AradhyaSambhuSatpathy, N. K. Kishore, Senior Member, IEEE, DebaprasadKastha, Member, IEEE, and N. C. Sahoo, Member, IEEE “Control Scheme for a Stand-Alone Wind Energy Conversion System" 


\section{BIOGRAPHIES}

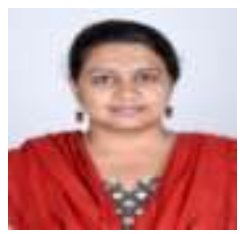

Nethravathi S Gaddi, Obtained BE degree from VTU in 2009. Currently pursuing master degree in University BDT college of Engineering, Davangere, Karnataka, India.

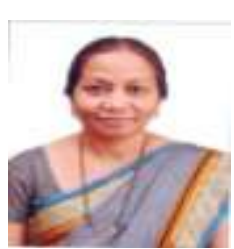

Smt. A.V. Malini, received BE in Electrical Engineering from GBDT college of Engineering in 1985 and ME in 1990 from UVCE and currently working as Associate professor in University BDT college of Engineering, Davangere. Her Area of interest are Power system planning, generation and economic operation. 